Article

\title{
Highly Crystallized Pd/Cu Nanoparticles on Activated Carbon: An Efficient Heterogeneous Catalyst for Sonogashira Cross-Coupling Reaction
}

\author{
Zhen Wei ${ }^{1}$, Zunyuan Xie ${ }^{1, *}$, Lingxiang Gao ${ }^{1}$, Yanyan Wang ${ }^{1}{ }^{\circledR}$, Huaming Sun ${ }^{1}$, Yajun Jian ${ }^{1}$, \\ Guofang Zhang ${ }^{1}$, Liwen Xu ${ }^{1}$, Jianming Yang ${ }^{2}$, Weiqiang Zhang ${ }^{1, *(D)}$ and Ziwei Gao ${ }^{1, *}$ \\ 1 Key Laboratory of Applied Surface and Colloid Chemistry MOE, School of Chemistry and Chemical \\ Engineering, Shaanxi Normal University, Xi'an 710062, China; weizhen@snnu.edu.cn (Z.W.); \\ gaolx@snnu.edu.cn (L.G.); yyw@snnu.edu.cn (Y.W.); hmsun@snnu.edu.cn (H.S.); \\ yajunjian@snnu.edu.cn (Y.J.); gfzhang@snnu.edu.cn (G.Z.); liwenxu@hznu.edu.cn (L.X.); \\ yangjm204@163.com (J.Y.) \\ 2 Xi' an Modern Chemistry Research Institute, Xi'an 710065, China \\ * Correspondence: zyxie123@snnu.edu.cn (Z.X.); zwq@snnu.edu.cn (W.Z.); zwgao@snnu.edu.cn (Z.G.)
}

Received: 29 December 2019; Accepted: 27 January 2020; Published: 5 February 2020

\begin{abstract}
In the quest for efficient and recyclable heterogeneous catalysts for Sonogashira coupling reactions, a PEG-OMe (Methoxy Polyene Glycol) - mediated method was developed to immobilize $\mathrm{Pd} / \mathrm{Cu}$ bimetallic nanoparticles on activated carbon (AC). Catalytic experiments showed that $\mathrm{Pd} / \mathrm{Cu} @ \mathrm{AC}$ prepared in a PEG-OMe 500 had the highest activity. The morphology and composition of the catalyst were determined, and the identified crystallized and heterometallic nanoparticles of $\mathrm{Pd} / \mathrm{Cu}$ were essential for an efficient catalytic cycle. The Pd/Cu@AC catalyst was successfully used in Sonogashira reactions (21 examples) including with aryl bromides as the coupling partner in EtOH at $80-100{ }^{\circ} \mathrm{C}$. The catalyst was recycled at least nine times.
\end{abstract}

Keywords: palladium copper bimetallic catalyst; activated carbon; solvothermal reduction; Sonogashira coupling reaction

\section{Introduction}

The Csp-Csp ${ }^{2}$ cross-coupling reaction, also known as a Sonogashira reaction, has gained much attention because alkynes are important precursors of various pharmaceuticals, natural products, and organic materials [1-3]. Despite many attempts to develop a transition-metal-catalyzed Sonogashira coupling reaction using a single metal, such as $\mathrm{Cu}[4,5], \mathrm{Fe}[6,7], \mathrm{Ni}[8,9]$, and $\mathrm{Au}[10-14]$, most of today's transition-metal-catalyzed cross-coupling chemistry still relies on a bimetallic catalyst system of $\mathrm{Pd}$ and $\mathrm{Cu}$. In the putative catalytic cycle of a Sonogashira reaction, $\mathrm{Pd}$ and $\mathrm{Cu}$ are responsible for the oxidative addition of a $\mathrm{C}-\mathrm{X}$ bond and the transmetalation of an activated triple bond, respectively $[15,16]$. The $\mathrm{Pd} / \mathrm{Cu}$ bimetallic catalyst system has excellent redox properties, probably because of the electron-donating and -accepting characteristics of $\mathrm{Cu}$ and $\mathrm{Pd}$, respectively $[17,18]$. The "Cu effect" represents an adjustment or modification of the catalytic ability in Pd-catalyzed Sonogashira coupling reactions [19-21]. Recently, several Pd/Cu bimetallic nanoparticles (NPs) were loaded on commercially available insoluble organic or inorganic supports as heterogeneous catalysts, and were successfully used in cross-coupling reactions and other chemical reactions [22-39]. Supported bimetallic NP catalysts with minimal or no leaching are necessary for both environmental protection and cost reduction. In other words, it is essential to develop solid-supported $\mathrm{Pd} / \mathrm{Cu}$ bimetallic NP heterogeneous catalysts using easily available raw materials and simple procedures and with a high catalytic efficiency. 
The chemical reductant and solvent of a catalyst system are essential factors to tune the morphology and catalytic activity of heterogeneous Pd catalysts. For a bimetallic $\mathrm{Pd} / \mathrm{Cu}$ catalyst system, a strong reductant such as sodium borohydride ( $\mathrm{NaBH} 4$ ) [34] is used to generate highly uniform $\mathrm{Pd} / \mathrm{Cu}$ composites. Diverse milder reductants are also used to reduce metal salts, such as DMF [26,28], toluene [36], ethanol [27-30], and morpholine [35]. The solvent of a catalyst system interacts with the reactants, intermediates, and final products, thus significantly affecting the reaction results. The compatible properties of polyols, water, DMF, oleylamine (OAm), and benzene with common reactants make it possible to use them as solvents and structure modulators to synthesize metal NPs. Interestingly, amines such as DMF, OAm, and polyols can serve as both reductant and solvent [40-42].

Polymeric oxygenated solvents such as dioxane and ethylene glycol (EG) with oxygen and hydroxyl groups can reduce $\mathrm{Pd} / \mathrm{Cu}$ precursors under thermal conditions [9m]. We hypothesized that the polymeric oxygenated solvent PEG-OMe can be used as both reductant and solvent to fabricate uniform $\mathrm{Pd} / \mathrm{Cu}$ bimetallic catalysts. To the best of our knowledge, PEG-OMe-mediated fabrication of bimetallic Pd/Cu NPs impregnated on activated carbon (AC) and their heterogeneous catalytic activity in cross-coupling reactions have not been reported. Carbonaceous material such as AC is commercially available, inexpensive, has a large surface area, is stable, and separates easily, and therefore could be an excellent support. Here, we report the synthesis and characterization of a new class of heterogeneous $\mathrm{Pd} / \mathrm{Cu}$ bimetallic NPs supported on AC. This catalyst showed efficient catalytic activity in Sonogashira cross-coupling reactions under mild reaction conditions, and had high recyclability.

\section{Results and Discussion}

The thermal solvolysis of transition-metal salts in reductive solvents led to the formation of the corresponding NPs. To finely control the composition of $\mathrm{Pd} / \mathrm{Cu}$ NPs, organic solvents bearing multi-dentated oxygen donors were used to fabricate $\mathrm{Pd} / \mathrm{Cu} @ A C$ catalysts. As shown in Figure 1a, the XRD patterns of $\mathrm{Pd}$ and $\mathrm{Cu}$ were identified by comparing them with that of amorphous $\mathrm{AC}$. Angles of $2 \theta$ at $40.1^{\circ}, 46.59^{\circ}$, and $68.11^{\circ}$ were assigned to Pd (111), (200), and (220) planes, respectively (JCPDS\#5-681), and $2 \theta$ angles of $43.34^{\circ}, 50.46^{\circ}$, and $73.99^{\circ}$ correspond to $\mathrm{Cu}(111),(200)$, and (220) planes, respectively (JCPDS\#4-836) (Figure 1b). The reductive solvents significantly affected the crystallization of deposited metallic NPs. In ethanol (Cat 1), only Pd0 deposited on the AC support. With the increase in the length of PEG chains such as PEG 300, PEG-OMe 350, and PEG-OMe 500, the loading of $\mathrm{Cu} 0$ increased accordingly. Interestingly, the crystallization of supported metallic NPs was also dependent on the PEGylated solvents. The results indicate that the coordination effect of metal ions with PEGylated solvents induced the aggregation and assembly of $\mathrm{Pd} 0$ and $\mathrm{Cu} 0$, perhaps because the coordination ability of the $\mathrm{O}$ atoms of the solvent helped to capture the metal ions. Cat 5 prepared in PEG-OMe 500 showed the highest crystallization of Pd/Cu NPs, with sharper and more intensive peaks than others.

The STEM-EDS mapping images (Figure 2) of Pd and $\mathrm{Cu}$ show that $\mathrm{Pd}$ and $\mathrm{Cu}$ homogeneously dispersed on the surface of AC support, respectively. The high-resolution TEM (HRTEM) images of $\mathrm{Pd} / \mathrm{Cu} @ \mathrm{AC}$ show that the metallic NPs aggregated on the Cu network after the ultrasonic dispersion of the catalyst (Figure 3A). The particle-size distribution analysis (Figure 3B) indicates that the average diameter of these particles was $\sim 9.3 \mathrm{~nm}$. Three types of lattice with a void image (Figure 3C) correspond to the pure $\mathrm{Pd}(111)(0.2265 \mathrm{~nm}), \mathrm{Pd}(200)(0.1945 \mathrm{~nm})$, and $\mathrm{Cu}(111)(0.2088 \mathrm{~nm})$ planes. These results indicate the coexistence of $\mathrm{Pd}$ and $\mathrm{Cu}$ NPs on the surface of $\mathrm{AC}$, and slight variations of $\mathrm{d}$-spacing might result from the heterometallic interaction between $\mathrm{Pd}$ and $\mathrm{Cu}$. 


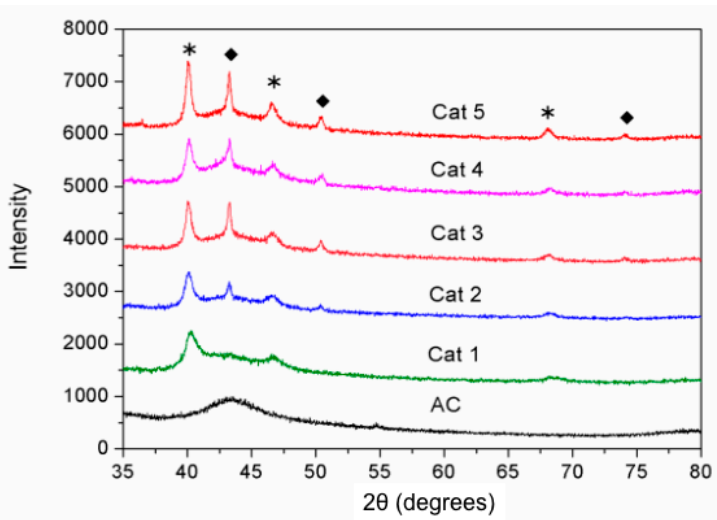

(a)

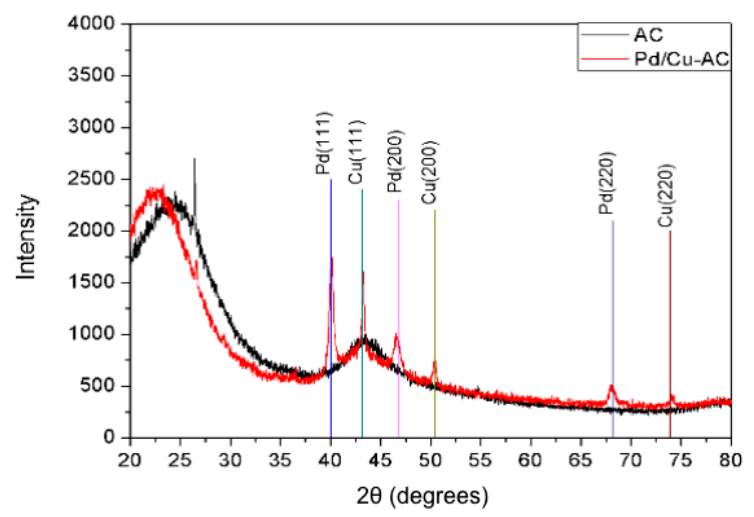

(b)

Figure 1. (a) XRD patterns of activated carbon (AC) and Pd/Cu@AC catalysts prepared using different solvents: (Cat 1) EtOH, (Cat 2) ethylene glycol (EG), (Cat 3) PEG 300, (Cat 4) PEG-OMe 350, and (Cat 5) PEG-OMe 500. (*) Diffraction of Pd in Pd/Cu@AC and ( ) diffraction of $\mathrm{Cu}$ in Pd/Cu@AC; (b) XRD patterns of AC and Cat 5 PEG-OMe 500.

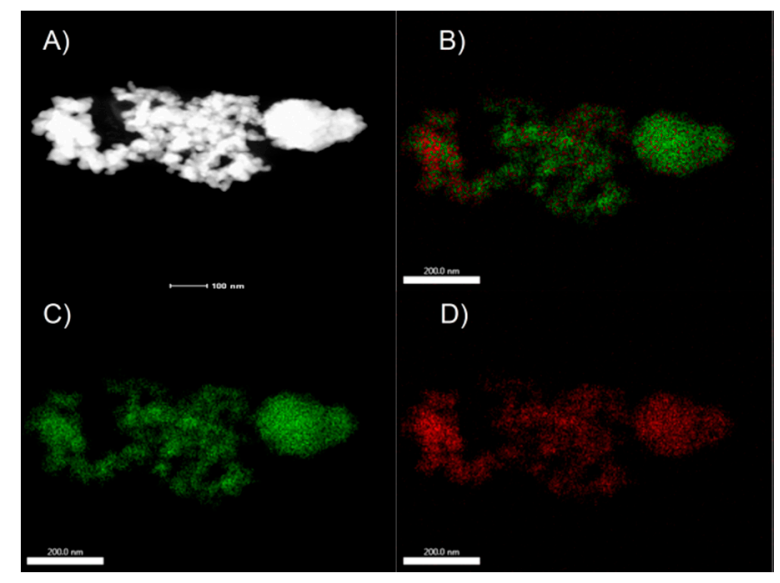

Figure 2. (A) STEM images and STEM-EDS mapping images of (B) $\mathrm{Pd} / \mathrm{Cu},(\mathbf{C}) \mathrm{Pd}$, and (D) $\mathrm{Cu}$ of the as-prepared Pd/Cu@AC.

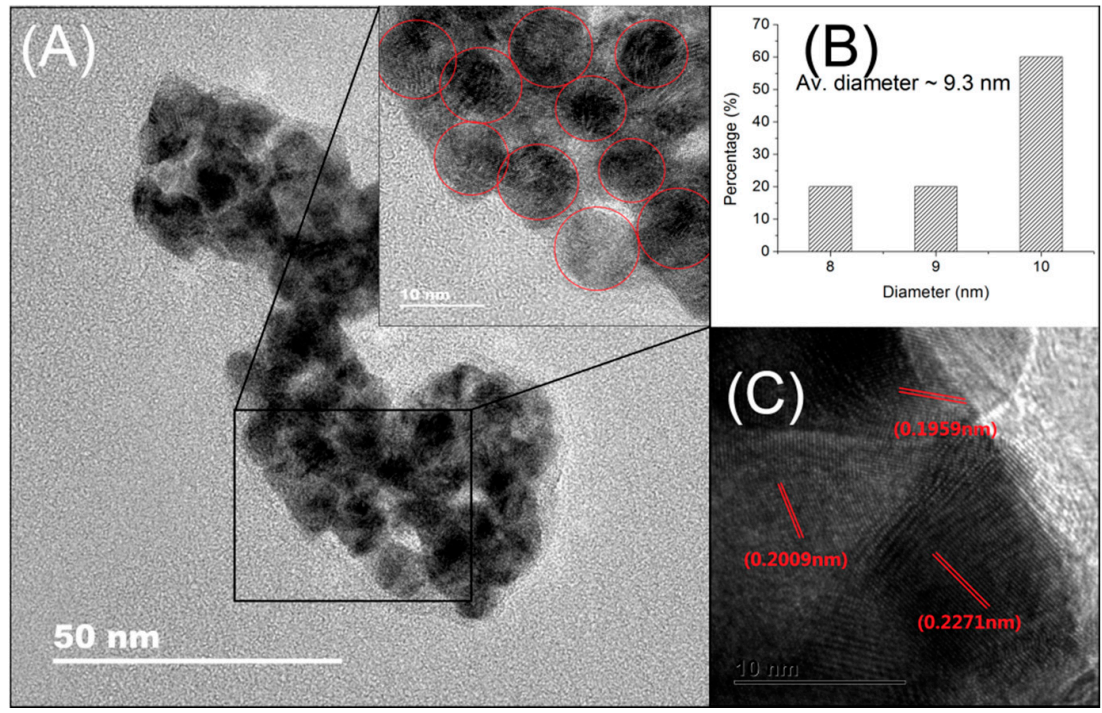

Figure 3. (A) TEM image of $\mathrm{Pd} / \mathrm{Cu} @ \mathrm{AC}$; (B) particle-size distribution evaluated from (A); (C) high-resolution TEM (HRTEM) image of a part of (B). 
XPS measurements for the surface composition of Pd/Cu@AC revealed the valence state of metal NPs. Figure 4 shows the XPS spectra of Pd $3 d$ and $\mathrm{Cu} 2 \mathrm{p}$ in Pd/Cu@AC. The splitting pattern of Pd $3 \mathrm{~d}$ showed two triple peaks around 332 to $348 \mathrm{eV}$, corresponding to the $\mathrm{Pd} 3 \mathrm{~d} 5 / 2$ and $\mathrm{Pd} 3 \mathrm{~d} 3 / 2$, respectively. The two lower binding energies at 335.4 and $340.7 \mathrm{eV}$ were related to metallic Pd0, whereas the other two sets of peaks at $336.06 \mathrm{eV}, 341.36 \mathrm{eV}$, and at $337.36 \mathrm{eV}, 342.89 \mathrm{eV}$, were related to two types of $\mathrm{Pd}$ oxidant [43]. In Figure 3B, the binding energy of $\mathrm{Cu} 2 \mathrm{p} 3 / 2$ peak was observed at $932.08 \mathrm{eV}$, and the $\mathrm{Cu}$ $2 \mathrm{p} 1 / 2$ peak centered at $952.01 \mathrm{eV}$ was attributed to $\mathrm{Cu} 0$ or $\mathrm{Cu}+$. The shoulder observed on $\mathrm{Cu} 2 \mathrm{p}$ peak can be assigned to $\mathrm{CuO}$. However, probably because of a small amount of $\mathrm{CuO}$, the satellite peaks of $\mathrm{CuO}$ at $940-945 \mathrm{eV}$ were not observed [44].
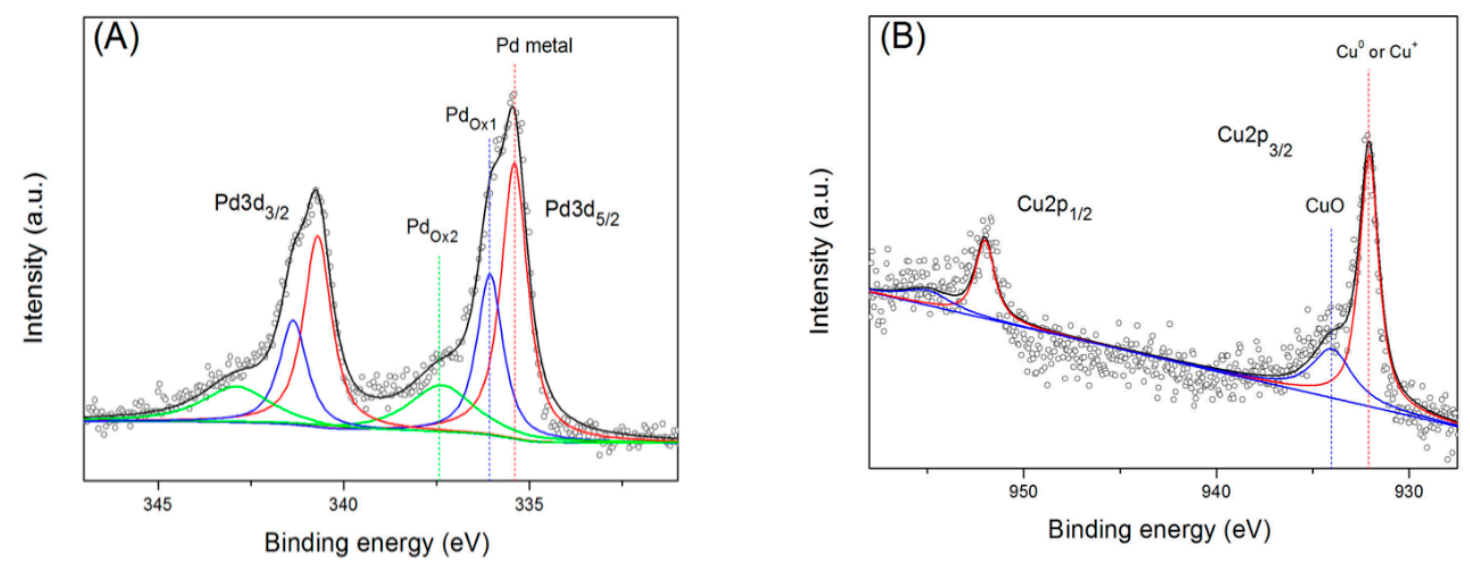

Figure 4. Core-shell XPS spectra of (A) Pd $3 d$ and (B) Cu $2 p$.

The activity of Pd/Cu@AC catalysts was evaluated for Sonogashira coupling. Initially, 4-iodotoluene and phenylacetylene were selected for the model reaction to test the activity of Cat $1-C a t 5$. As shown in Table 1, Cat 1 prepared using EtOH provided an $87 \%$ yield, whereas Cat 2 provided less yield $(80 \%)$ even though an XRD peak for $\mathrm{Cu}$ was clearly observed in Figure 1 . This indicates that Pd had a major influence on the bimetallic catalysts of Sonogashira cross-coupling reactions. Furthermore, the activity of catalysts produced by polymeric solvents was better than other catalysts. The activities of solvothermally prepared monometallic catalysts, Pd@AC and Cu@AC (both produced in PEG-OMe 500 ), were also evaluated. They afforded products in $50 \%$ and $61 \%$ yields, respectively, much less than Pd/Cu@AC (up to 98\% yield). The controlled experiments with mixtures of Pd@Ac and Cu@Ac as catalysts afforded a $67 \%$ yield, showing the superior activity of heterometallic catalysts. These results clearly indicate that the cooperative catalysis of $\mathrm{Pd}$ and $\mathrm{Cu}$ was essential to achieve a significant improvement in catalytic Csp2-Csp coupling reactions. The best result was obtained in the presence of Cat 5, 2 equiv of $\mathrm{K}_{2} \mathrm{CO}_{3}$, and $5 \mathrm{~mol} \%$ of $\mathrm{PPh}_{3}$ in $\mathrm{EtOH}$ and $\mathrm{N} 2$ atmosphere at $80{ }^{\circ} \mathrm{C}$ for $12 \mathrm{~h}$. Therefore, PEG-OMe 500 is an ideal solvent for the preparation of active $\mathrm{Pd} / \mathrm{Cu} @ \mathrm{AC}$ catalysts, providing the highest crystallization of both $\mathrm{Pd}$ and $\mathrm{Cu}$.

To investigate the scope and limitations of $\mathrm{Pd} / \mathrm{Cu} @ \mathrm{AC}$ catalyst, the Sonogashira coupling reactions of various aryl iodides/bromides and phenyl/aliphatic acetylenes catalyzed by Cat 5 were studied under the optimized reaction conditions, and the results are shown in Table 2. 
Table 1. Pd/Cu@AC catalyzed cross-coupling of 4-iodotoluene and phenylacetylene.

\begin{tabular}{ccc}
\hline Entry & Catalysts & Isolated Yield [\%] \\
\hline 1 & Cat 1 & 87 \\
2 & Cat 2 & 80 \\
3 & Cat 3 & 83 \\
4 & Cat 4 & 89 \\
5 & Cat 5 & 98 \\
6 & Pd@AC & 50 \\
7 & Cu@AC & 61 \\
8 & Pd@AC+Cu@AC & 67 \\
\hline
\end{tabular}

${ }^{1}$ Condition: 4-iodotoluene $(0.5 \mathrm{mmol})$, phenylacetylene $(0.6 \mathrm{mmol})$, catalysts $(\mathrm{Pd}, 3 \mathrm{~mol} \%), \mathrm{K}_{2} \mathrm{CO}_{3}(1.0 \mathrm{mmol}), \mathrm{EtOH}$ (5 mL), $\mathrm{PPh}_{3}(5.0 \mathrm{~mol} \%), 12 \mathrm{~h}, 80^{\circ} \mathrm{C}, \mathrm{N}_{2}$ atmosphere.

Table 2. Sonogashira cross-coupling of aryl halides and terminal alkynes catalyzed by Pd/Cu@AC.

\begin{tabular}{|c|c|c|c|c|c|c|c|}
\hline & & $A r-X+R-$ & $\bar{\equiv} \frac{\text { Cat }}{\mathrm{E}}$ & $\underset{\mathrm{H}, \mathrm{N}_{2}}{\stackrel{\mathrm{L}, \mathrm{K}_{2} \mathrm{CO}_{3}}{\longrightarrow}}$ & $\mathrm{Ar}=$ & & \\
\hline Entry & Ar-X & $\mathbf{R}$ & Yield $[\%]^{c}$ & Entry & Ar-X & $\mathbf{R}$ & Yield $[\%]^{c}$ \\
\hline 1 & & $\mathrm{C}_{6} \mathrm{H}_{5}$ & 97 & 12 & & $3-\mathrm{ClC}_{6} \mathrm{H}_{4}$ & 77 \\
\hline 2 & & $\mathrm{C}_{6} \mathrm{H}_{5}$ & 96 & 13 & & $4-\mathrm{ClC}_{6} \mathrm{H}_{4}$ & 84 \\
\hline 3 & & $\mathrm{C}_{6} \mathrm{H}_{5}$ & 90 & 14 & & $4-\mathrm{BrC}_{6} \mathrm{H}_{4}$ & 65 \\
\hline 4 & & $\mathrm{C}_{6} \mathrm{H}_{5}$ & 90 & 15 & & $n-\mathrm{C}_{6} \mathrm{H}_{13}$ & 66 \\
\hline 5 & & $\mathrm{C}_{6} \mathrm{H}_{5}$ & 96 & 16 & & $n-\mathrm{C}_{5} \mathrm{H}_{11}$ & 84 \\
\hline 6 & & $\mathrm{C}_{6} \mathrm{H}_{5}$ & 91 & 17 & & $n-\mathrm{C}_{4} \mathrm{H}_{9}$ & 96 \\
\hline 7 & & $\mathrm{C}_{6} \mathrm{H}_{5}$ & 92 & $18^{b}$ & & $\mathrm{C}_{6} \mathrm{H}_{5}$ & 94 \\
\hline 8 & & $\mathrm{C}_{6} \mathrm{H}_{5}$ & 99 & $19^{b}$ & & $\mathrm{C}_{6} \mathrm{H}_{5}$ & 65 \\
\hline 9 & & $4-\mathrm{C}_{2} \mathrm{H}_{5} \mathrm{C}_{6} \mathrm{H}_{4}$ & 95 & $20^{b}$ & & $\mathrm{C}_{6} \mathrm{H}_{5}$ & 46 \\
\hline 10 & & $3-\mathrm{MeC}_{6} \mathrm{H}_{4}$ & 64 & $21^{b}$ & & $\mathrm{C}_{6} \mathrm{H}_{5}$ & 51 \\
\hline 11 & & $4-\mathrm{MeC}_{6} \mathrm{H}_{4}$ & 97 & \multicolumn{4}{|c|}{$\begin{array}{l}\text { Conditions: Ar- } \mathrm{X}(0.5 \mathrm{mmol}), \mathrm{RC} \equiv \mathrm{CH}(0.6 \mathrm{mmol}), \\
\text { Cat } 5(53 \mathrm{mg}, \mathrm{Pd} 3 \mathrm{~mol} \%), \mathrm{K}_{2} \mathrm{CO}_{3} \text { ( } 2 \text { equiv), } \mathrm{PPh}_{3} \\
(5 \mathrm{~mol} \%), \mathrm{EtOH}(5 \mathrm{~mL}), 80^{\circ} \mathrm{C}, 12 \mathrm{~h}, \mathrm{~N}_{2} \text { atmosphere. } \\
{ }^{b} \text { X-Phos }(5 \mathrm{~mol} \%), 100{ }^{\circ} \mathrm{C}, 24 \mathrm{~h} .^{c}{ }^{c} \text { Isolated yields. }\end{array}$} \\
\hline
\end{tabular}

The cross-couplings of aliphatic or aryl alkynes with aryl iodides afforded products in reasonable yields (Table 2, entries 1-14). Both the electron-rich and-deficient aryl iodides afforded products in 
moderate-to-excellent yields (Table 2, entries 1-6). The aryl iodides bearing electro-donating groups such as -Ome (methoxy), -Me (methyl) and - $\mathrm{COMe}\left(\mathrm{O}=\mathrm{CCH}_{3}\right)$ afforded satisfactory yields (Table 2, entries 1-4). The highest yields were provided by 1-iodonaphthalene and 2-iodothiophene, with $92 \%$ and $99 \%$ yields, respectively. On the other hand, phenylalkynes bearing electron-donating/withdrawing groups provided good results (Table 2, entries 9-14). Aliphatic acetylenes were also successfully coupled to 4 -iodoanisole, with yields higher than $60 \%$. The 1-Hexyne provided a $96 \%$ yield; the 1-heptyne and 1-octyne provided $84-66 \%$ yields (Table 2, entries $15-17$ ).

The above-mentioned procedure was ineffective for less-active aryl bromides. Considering the effect of ligands, six phosphine ligands were selected (Table S1). Notably, Cat 5 successfully catalyzed the cross-coupling of aryl bromides and phenyl acetylene using X-Phos as the ligand at $100{ }^{\circ} \mathrm{C}$ for $24 \mathrm{~h}$, affording moderate-to-excellent yields (Table 2, entries 18-21).

Reusability of catalysts is essential for developing heterogeneous catalysts. In this regard, a recycling test was performed for the $\mathrm{Pd} / \mathrm{Cu} @ \mathrm{AC}$ catalyst. The catalyst was easily separated by the centrifugation of the reaction mixture. The isolated yields were measured for nine cycles. After eight cycles, the catalyst maintained $99 \%$ yields. In the 9 th catalytic experiment, the recycled catalyst provided $87 \%$ yield. These results clearly indicate the sustainability of the bimetallic catalyst. The Pd and $\mathrm{Cu}$ concentrations in the solution were analyzed during each cycle by ICP-MS (Figure 5). The catalyst leached 0.5-1.3 ppm of Pd for each cycle, while the $\mathrm{Cu}$ leaching was faster. During the first experiment, the $\mathrm{Cu}$ concentration was $30 \mathrm{ppm}$, and sharply decreased to $<8 \mathrm{ppm}$ in the next three cycles. After 9th recycle experiment, the SEM image of recycled $\mathrm{Pd} / \mathrm{Cu} @ \mathrm{AC}$ was obtained and compared with fresh catalyst. An obvious aggregation was shown, and it probably led to the yield-decreasing in the 9th recycle and subsequent inactivation.

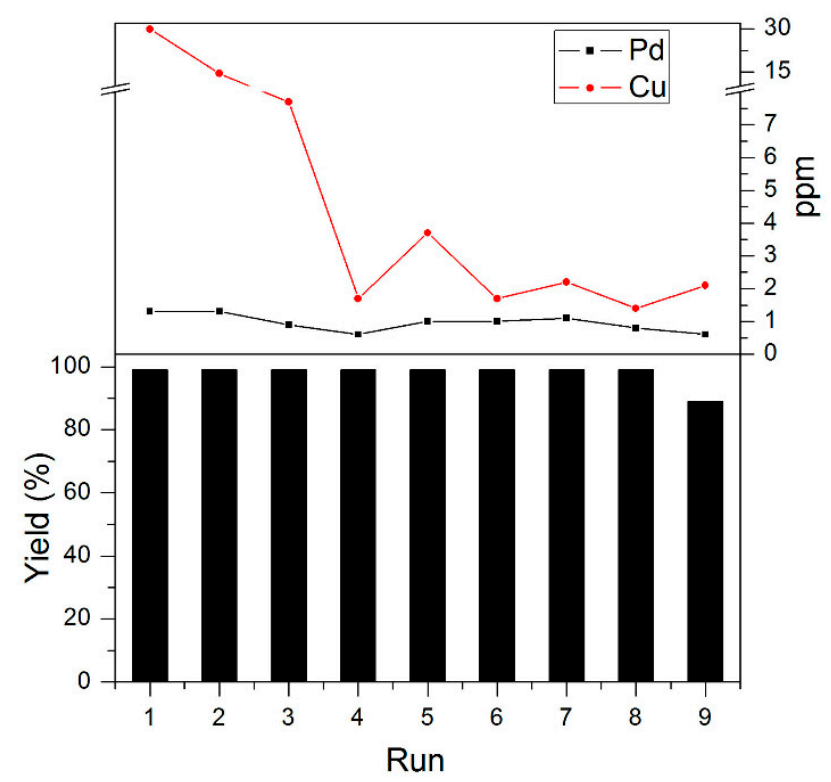

Figure 5. Recycling experiments using $\mathrm{Pd} / \mathrm{Cu} @ \mathrm{AC}$ in the cross-coupling reaction between 4-iodotoluene and phenylacetylene, and the ICP-MS results of $\mathrm{Pd} / \mathrm{Cu}$ leaching in the solution of 1-9 cycles. The yields were determined by $1 \mathrm{H}-\mathrm{NMR}$.

The control experiments using 0.5 ppm Pd and 1 ppm Cu afforded less than $41 \%$ yields. However, the $\mathrm{Pd}$ and $\mathrm{Cu}$ concentrations did not clearly change in the 9th recycle with yield decline, ruling out the possibility that the leached $\mathrm{Pd}$ and $\mathrm{Cu}$ were the catalytic species. These results showed that the supported bimetallic Pd/Cu NPs were responsible for the catalytic activity. 


\section{Materials and Methods}

\subsection{Preparation of Catalysts}

Bimetallic Pd/Cu@AC catalysts were prepared as follows: typically, $\mathrm{Pd}(\mathrm{II})$ acetate $\left(\mathrm{Pd}(\mathrm{OAc})_{2}\right.$ : $63.3 \mathrm{mg}, 0.28 \mathrm{mmol}), \mathrm{Cu}(\mathrm{II})$ nitrate trihydrate $\left(\mathrm{Cu}\left(\mathrm{NO}_{3}\right)_{2} \bullet 3 \mathrm{H}_{2} \mathrm{O}: 68.1 \mathrm{mg}, 0.28 \mathrm{mmol}\right)$, and $\mathrm{AC}(1 \mathrm{~g})$ were dispersed in $30 \mathrm{~mL}$ of different solvents: EtOH (Cat 1), EG (Cat 2), PEG 300 (Cat 3), PEG-OMe 350 (Cat 4), and PEG-OMe 500 (Cat 5). Then, the mixture was heated in a Teflon-lined stainless-steel autoclave at $170{ }^{\circ} \mathrm{C}$ for $24 \mathrm{~h}$. The catalyst was separated by decantation, washed with EtOH $(30 \mathrm{~mL}$, 5 times), and dried at $50{ }^{\circ} \mathrm{C}$ in an electrothermostatic blast oven.

\subsection{General Procedure for Sonogashira Reactions}

In a Schlenk tube, $\mathrm{K}_{2} \mathrm{CO}_{3}(1.0 \mathrm{mmol}, 2$ equiv), catalyst ( $3 \mathrm{~mol} \% \mathrm{Pd})$, and ligand (5 $\mathrm{mol}^{\circ} \mathrm{PPh}_{3}$ or X-Phos) were added under $\mathrm{N}_{2}$ atmosphere. $\mathrm{EtOH}(5 \mathrm{~mL})$ was transferred using a cannula. After adding the terminal alkyne ( $0.6 \mathrm{mmol}, 1.2$ equiv) and aryl halide $(0.5 \mathrm{mmol}, 1$ equiv), the resulting mixture was stirred under N2 atmosphere at $80^{\circ} \mathrm{C}$ for $12 \mathrm{~h}$, or at $100^{\circ} \mathrm{C}$ for $24 \mathrm{~h}$. The products were isolated via flash chromatography with a selected eluent, such as Hexane: dichloromethane. For instance, after the reaction finished, the solid silica-gel was added into reaction mixture. The solvent was removed under vacuum. The solid residue was loaded on the column filled with a silica gel of 200 mesh. A fraction of the product band was collected. The pure product was contained after the eluent was removed. The pure product was characterized by 1HNMR and 13NMR [26].

\subsection{Recycling Experiments}

After each catalytic reaction, the catalyst was separated by centrifugation and filtration, washed with $\mathrm{H}_{2} \mathrm{O}(3 \mathrm{~mL})$ and $\mathrm{EtOH}\left(9 \mathrm{~mL}, 3\right.$ times), and dried at $50{ }^{\circ} \mathrm{C}$ for further recycling experiments. The catalytic experiments using the recycled catalysts were carried out under the same conditions as those of general procedure for the Sonogashira reactions.

\section{Conclusions}

A facile PEG-OMe-mediated solvothermal method was developed to fabricate highly crystallized $\mathrm{Pd} / \mathrm{Cu}$ NP catalysts. Pd/Cu@AC (Cat 5) was prepared by supporting Pd/Cu based bimetallic NPs on AC using PEG-OMe 500. Cat 5 showed the best activity and recyclability in Sonogashira cross-coupling reactions. The catalyst was compatible with diverse aryl iodides and bromides, with moderate-excellent yields, and could be recycled at least nine times. The recyclability was consistent with the low-ppm leaching of supported metallic compositions. The AC-supported catalysts have several advantages, such as their recyclability, easy operation, and environmental friendliness, over conventional $\mathrm{Pd}$ catalysts. The Pd/Cu@AC catalysts may find applications in various other C-C coupling reactions.

Supplementary Materials: The following are available online at http://www.mdpi.com/2073-4344/10/2/192/s1, Figure S1: The XRD patterns of the activated carbon (AC) and Pd/Cu@AC Cat 5; Table S1: The reaction results between 4-Bromoanisole and phenylacetylene; NMR spectra data for the Sonogashira-cross coupling products.

Author Contributions: Conceptualization, Z.X., W.Z., and Z.G.; methodology, Z.W. and Z.X.; validation, Z.W., Y.W., J.Y., and H.S.; formal analysis, G.Z., W.Z., and L.X.; investigation, Z.W.; writing-original draft preparation, Z.W.; writing-review and editing, Z.X., L.G., and Y.J.; supervision, L.X., W.Z., and Z.G.; project administration, W.Z. All authors have read and agreed to the published version of the manuscript.

Funding: This research was supported by grants from National Natural Science Foundation of China (21771122, 21602129, 21571121), the 111 Project (B14041), Key Research and Development Project of Shaanxi Science and Technology Department (2017SF-064, 2017GY-124), Fundamental Research Funds for the Central Universities under Grant (GK201903026), and Projects of Xi' an Modern Institute of Chemistry (204-J-2018-315-4/6, 204-J-2019-0387-3/6-6).

Conflicts of Interest: The authors declare no conflicts of interest. 


\section{References}

1. Chinchilla, R.; Nájera, C. The Sonogashira Reaction: A Booming Methodology in Synthetic Organic Chemistry. Chem. Rev. 2007, 107, 874-922. [CrossRef] [PubMed]

2. Chinchilla, R.; Nájera, C. Recent advances in Sonogashira reactions. Chem. Soc. Rev. 2011, 40, 5084-5121. [CrossRef] [PubMed]

3. Wang, D.; Gao, S.H. Sonogashira coupling in natural product synthesis. Org. Chem. Front. 2014, 1, 556-566. [CrossRef]

4. Thomas, A.M.; Sujatha, A.; Anilkumar, G. Recent advances and perspectives in copper catalyzed Sonogashira coupling reactions. RSC Adv. 2014, 4, 21688-21698. [CrossRef]

5. Gawande, M.B.; Goswami, A.; Felpin, F.X.; Asefa, T.; Huang, X.; Silva, R.; Zou, X.; Zboril, R.; Varma, R.S. $\mathrm{Cu}$ and $\mathrm{Cu}-$ Based Nanoparticles: Synthesis and Applications in Catalysis. Chem. Rev. 2016, 116, 3722-3811. [CrossRef]

6. Carril, M.; Correa, A.; Bolm, C. Iron-Catalyzed Sonogashira Reactions. Angew. Chem. Int. Ed. 2008, 47, 4862-4865. [CrossRef]

7. Hatakeyama, T.; Okada, Y.; Yoshimoto, Y.; Nakamura, M. Tuning Chemoselectivity in Iron-Catalyzed Sonogashira-Type Reactions Using a Bisphosphine Ligand with Peripheral Steric Bulk: Selective Alkynylation of Nonactivated Alkyl Halides. Angew. Chem. Int. Ed. 2011, 50, 10973-10976. [CrossRef]

8. Wang, L.; Lia, P.; Zhang, Y. The Sonogashira coupling reaction catalyzed by ultrafine nickel(0) powder. Chem. Commun. 2004, 514-515. [CrossRef]

9. Tobisu, M.; Chatani, N. Cross-Couplings Using Aryl Ethers via C-O Bond Activation Enabled by Nickel Catalysts. Acc. Chem. Res. 2015, 48, 1717-1726. [CrossRef]

10. Kyriakou, G.; Beaumont, S.K.; Humphrey, S.M.; Antonetti, C.; Lambert, R.M. Sonogashira Coupling Catalyzed by Gold Nanoparticles: Does Homogeneous or Heterogeneous Catalysis Dominate? ChemCatChem 2010, 2 , 1444-1449. [CrossRef]

11. Lauterbach, T.; Livendahl, M.; Rosellón, A.; Espinet, P.; Echavarren, A.M. Unlikeliness of Pd-Free Gold(I)-Catalyzed Sonogashira Coupling Reactions. Org. Lett. 2010, 12, 3006-3009. [CrossRef] [PubMed]

12. Kanuru, V.K.; Kyriakou, G.; Beaumont, S.K.; Papageorgiou, A.C.; Watson, D.J.; Lambert, R.M. Sonogashira Coupling on an Extended Gold Surface in Vacuo: Reaction of Phenylacetylene with Iodobenzene on Au(111). J. Am. Chem. Soc. 2010, 132, 8081-8086. [CrossRef] [PubMed]

13. Beaumont, S.K.; Kyriakou, G.; Lambert, R.M. Identity of the Active Site in Gold Nanoparticle-Catalyzed Sonogashira Coupling of Phenylacetylene and Iodobenzene. J. Am. Chem. Soc. 2010, 132, 12246-12248. [CrossRef] [PubMed]

14. Lin, J.; Abroshan, H.; Liu, C.; Zhu, M.; Li, G.; Haruta, M. Sonogashira cross-coupling on the Au(1 11 1) and $\mathrm{Au}\left(\begin{array}{l}1 \\ 0\end{array}\right)$ facets of gold nanorod catalysts: Experimental and computational investigation. J. Catal. 2015, 330, 354-361. [CrossRef]

15. Karak, M.; Barbosa, L.C.A.; Hargaden, G.C. Recent mechanistic developments and next generation catalysts for the sonogashira coupling reaction. RSC Adv. 2014, 4, 53442. [CrossRef]

16. Beccalli, E.M.; Broggini, G.; Gazzola, S.; Mazza, A. Recent advances in heterobimetallic palladium(ii)/copper(ii) catalyzed domino difunctionalization of carbon-carbon multiple bonds. Org. Biomol. Chem. 2014, 12, 6767-6789. [CrossRef] [PubMed]

17. Shih, Z.Y.; Wang, C.W.; Xu, G.; Chang, H.T. Porous palladium copper nanoparticles for the electrocatalytic oxidation of methanol in directmethanol fuel cells. J. Mater. Chem. A 2013, 1, 4773-4778. [CrossRef]

18. Myers, S.V.; Frenkel, A.I.; Crooks, R.M. X-ray Absorption Study of PdCu Bimetallic Alloy Nanoparticles Containing an Average of $\sim 64$ Atoms. Chem. Mater. 2009, 21, 4824-4829. [CrossRef]

19. Espinet, P.; Echavarren, A.M. The Mechanisms of the Stille Reaction. Angew. Chem. Int. Ed. 2004, 43, 4704-4734.

20. Peng, Y.; Li, W.D.Z. cine Substitution and the Cu Effect in Stille Cross-Coupling Reactions: Mechanistic Perspectives and Synthetic Utility. Eur. J. Org. Chem. 2010, 35, 6703-6708.

21. Pérez-Temprano, M.H.; Casares, J.A.; Espinet, P. Bimetallic Catalysis using Transition and Group 11 Metals: An Emerging Tool for C-C Coupling and Other Reactions. Chem. Eur. J. 2012, 18, 1864-1884. [CrossRef] [PubMed] 
22. Corma, A.; García, H.; Primo, A. Palladium and copper supported on mixed oxides derived from hydrotalcite as reusable solid catalysts for the Sonogashira coupling. J. Catal. 2006, 241, 123-131. [CrossRef]

23. Cano, R.; Yus, M.; Ramón, D.J. Impregnated copper or palladium-copper on magnetite as catalysts for the domino and stepwise Sonogashira-cyclization processes: A straightforward synthesis of benzo[b] furans and indoles. Tetrahedron 2012, 68, 1393-1400. [CrossRef]

24. Cintas, P.; Cravotto, G.; Gaudino, E.C.; Orio, L.; Boffa, L. Reticulated Pd(II)/Cu(I) cyclodextrin complexes as recyclable green catalyst for Sonogashira alkynylation. Catal. Sci. Technol. 2012, 2, 85-87. [CrossRef]

25. Heshmatpour, F.; Abazari, R.; Balalaie, S. Preparation of monometallic (Pd, Ag) and bimetallic (Pd/Ag, Pd/Ni, $\mathrm{Pd} / \mathrm{Cu}$ ) nanoparticles via reversed micelles and their use in the Heck reaction. Tetrahedron 2012, 68, 3001-3011. [CrossRef]

26. Xu, W.; Sun, Y.L.; Guo, M.; Zhang, W.Q.; Gao, Z.W. Montmorillonite Supported Pd/Cu Bimetallic Nanoparticle Catalyzed Sonogashira Coupling. Chin. J. Org. Chem. 2013, 33, 820. [CrossRef]

27. Xu, W.; Sun, H.M.; Yu, B.; Zhang, G.F.; Zhang, W.Q.; Gao, Z.W. Sonogashira Couplings on the Surface of Montmorillonite-Supported Pd/Cu Nanoalloys. ACS Appl. Mater. Interfaces 2014, 6, 20261-20268. [CrossRef]

28. Kariuki, N.N.; Wang, X.; Mawdsley, J.R.; Ferrandon, M.S.; Niyogi, S.G.; Vaughey, J.T.; Myers, D.J. Colloidal synthesis and characterization of carbon-supported $\mathrm{Pd}-\mathrm{Cu}$ nanoparticle oxygen reduction electrocatalysts. Chem. Mater. 2010, 22, 4144-4152. [CrossRef]

29. Behmenyar, G.; Akın, A.N. Investigation of carbon supported Pd-Cu nanoparticles as anode catalysts for direct borohydride fuel cell. J. Power Sources 2014, 249, 239-246. [CrossRef]

30. Gong, Q.; Gong, S.; Zhang, T.; Cheng, X.; Li, H. Achieving High Activity and Stability of Carbon Supported Pd-Cu Alloyed Catalysts for Fuel Cell Applications. J. Electrochem. Soc. 2019, 166, F906-F913. [CrossRef]

31. Sengupta, D.; Saha, J.; De, G.; Basu, B. Pd/Cu bimetallic nanoparticles embedded in macroporous ion-exchange resins: An excellent heterogeneous catalyst for the Sonogashira reaction. J. Mater. Chem. A. 2014, 2, 3986-3992. [CrossRef]

32. Korzec, M.; Bartczak, P.; Niemczyk, A.; Szade, J.; Kapkowski, M.; Zenderowska, P.; Balin, K.; Lelątko, J.; Polanski, J. Bimetallic nano-Pd/PdO/Cu system as a highly effective catalyst for the Sonogashira reaction. J. Catal. 2014, 313, 1-8. [CrossRef]

33. Nasrollahzadeh, M.; Jalehb, B.; Ehsani, A. Preparation of carbon supported CuPd nanoparticles as novel heterogeneous catalysts for the reduction of nitroarenes and the phosphine-free Suzuki-Miyaura coupling reaction. New J. Chem. 2015, 39, 1148-1153. [CrossRef]

34. Gholinejad, M.; Ahmadi, J. Assemblies of Copper Ferrite and Palladium Nanoparticles on Silica Microparticles as a Magnetically Recoverable Catalyst for Sonogashira Reaction under Mild Conditions. ChemPlusChem 2015, 6, 973-979. [CrossRef]

35. Diyarbakir, S.; Can, H.; Metin, O. Reduced graphene oxide-supported CuPd alloy nanoparticles as efficient catalysts for the Sonogashira cross-coupling reactions. ACS Appl. Mater. Interfaces. 2015, 7, 3199-3206. [CrossRef]

36. Gholinejad, M.; Jeddi, N.; Pullithadathil, B. Agarose functionalized phosphorus ligand for stabilization of smallsized palladium and copper nanoparticles: Efficient heterogeneous catalyst for Sonogashira reaction. Tetrahedron 2016, 72, 2491-2500. [CrossRef]

37. Gholinejad, M.; Ahmadi, J.; Najera, C.; Seyedhamzeh, M.; Zareh, F.; Kompany-Zareh, M. Graphene Quantum Dots Modified $\mathrm{Fe}_{3} \mathrm{O}_{4}$ Nanoparticles Supported PdCu with Enhanced Catalytic Activity for Sonogashira Reaction. Chem CatChem 2017, 8, 1442-1449. [CrossRef]

38. Evangelisti, C.; Balerna, A.; Psaro, R.; Fusini, G.; Carpita, A.; Benfatto, M. Characterization of a Poly-4-vinylpyridine-Supported CuPd Bimetallic Catalyst for Sonogashira Coupling Reactions. ChemPhysChem 2017, 14, 1921-1928. [CrossRef]

39. Hronec, M.; Fulajtárováa, K.; Vávra, I.; Sotáka, T.; Mičusík, E.D.M. Carbon supported Pd-Cu catalysts for highly selective rearrangement of furfural to cyclopentanone. Appl. Catal. B Environ. 2016, 181, $210-219$. [CrossRef]

40. Jiao, S.; Xu, M.; Zhang, Y.; Pang, G.; Feng, S. Influence of Polyols on the Formation of Iron Oxide Nanoparticles in Solvothermal System. J. Nanosci. Nanotechnol. 2010, 10, 8405-8407. [CrossRef]

41. Xiong, J.; Cheng, G.; Qin, F.; Wang, R.; Chen, H.S.R. Tunable BiOCl hierarchical nanostructures for high-efficient photocatalysis under visible light irradiation. Chem. Eng. J. 2013, 220, 228-236. [CrossRef] 
42. Lai, J.; Niu, W.; Luque, R.; Xu, G. Solvothermal synthesis of metal nanocrystals and their applications. Nano Today 2015, 10, 240-267. [CrossRef]

43. Gabasch, H.; Hayek, K.; Klötzer, B.; Unterberger, W.; Kleimenov, E.; Teschner, D.; Zafeiratos, S.; Hävecker, M.; Knop-Gericke, A.; Schlögl, R.; et al. Methane Oxidation on Pd(111): In Situ XPS Identification of Active Phase. J. Phys. Chem. C 2007, 111, 7957-7962. [CrossRef]

44. Espinós, J.P.; Morales, J.; Barranco, A.; Caballero, A.; Holgado, J.P.; González-Elipe, A.R. Interface Effects for $\mathrm{Cu}, \mathrm{CuO}$, and $\mathrm{Cu}_{2} \mathrm{O}$ Deposited on $\mathrm{SiO}_{2}$ and $\mathrm{ZrO}_{2}$. XPS Determination of the Valence State of Copper in $\mathrm{Cu} / \mathrm{SiO}_{2}$ and $\mathrm{Cu} / \mathrm{ZrO}_{2}$ Catalysts. J. Phys. Chem. B 2002, 106, 6921-6929. [CrossRef]

(C) 2020 by the authors. Licensee MDPI, Basel, Switzerland. This article is an open access article distributed under the terms and conditions of the Creative Commons Attribution (CC BY) license (http://creativecommons.org/licenses/by/4.0/). 